mined in Flintshire, Derbyshire, Yorkshire, and Shropshire. Most of the pigs which have been found bear inscriptions, and some have been officially stamped showing that they had been desilverised. The iron-workings of the Roman period were concentrated in the Weald and in the Forest of Dean, and tin mining was carried out to a small extent in Cornwall.

\section{Velocity of Light}

Mr. M. E. J. GHeURy de Bray, 40 Westmount Road, Eltham Park, London, S.E.9, has published, in the form of a pamphlet entitled "La vitesse de la lumière ", a critical and documented discussion of the chief experiments made to determine this constant, from the pioneer work of Römer and of Bradley, down to the latest experiment devised by Michelson. The experiments are carefully analysed, and the accounts contain discussions of certain errors, obscurities, and irrelevancies which disfigure the presentation of the subject in many of the texts. The description of the observations of Römer and of Bradley is specially useful. The author presents a table which shows the results of some twenty-one experiments, beginning with that of Fizeau in 1849 and concluding with the recent work of Michelson. Of these experiments he decides, after critical consideration, that seven give trustworthy results. He divides these into two groups -experiments carried out on a short base line and those carried out on a long base line. The results are summarised as follows :

(1) Bases courtes ; inférieures a $4 \mathrm{Km}$.

$\begin{array}{lll}1879.5 & \text { Michelson } & 299.910 \\ 1882.7 & \text { Newcomb } & 299.860 \\ 1882.8 & \text { Michelson } & 299.853\end{array}$

(2) Bases longues; $23 \mathrm{Km}$. ei plus.

$\begin{array}{lll}1874.8 & \text { Cornu-Helmert } & 299.990 \\ 1902.4 & \text { Perrotin } & 299.901 \\ 1924.6 & \text { Michelson } & 299.802 \\ 1926.0 & \text { Michelson } & 299.796\end{array}$

The conclusion reached is that "un fait très remarquable est tout de suite révélé par cette classification : dans les deux groupes, la vitesse de la lumière diminue progressivement avec le temps, et le changement de vitesse est approximativement proportionnel à l'intervalle de temps correspondant". However this may be, there is no question that Mr. Gheury de Bray has provided a useful résumé of the literature dealing with a very difficult experimental problem.

\section{Ocean Newspapers}

SINCE the first issue of the Transatlantic Times, which appeared in the form of a leaflet on the s.s. St. Paul on Nov. 15, 1899, maritime journalism has made great progress. All newspapers issued on British ships are now published by an organisation known as the Wireless Press. In the first place, it supplies ships with copies of the journals prepared in such a way that the news can be printed on board ship as it is received by the ship's radio operator. Rugby Radio, the G.P.O. wireless station, daily transmits three news bulletins-in the early morning, at midday, and during the evening. It also transmits a Saturday night message giving the League football results. This message is in keen demand among the crews on cargo boats all over the world. In the case of general elections, big races, and other events of world-wide interest, it often happens that a passenger in midAtlantic is reading the results before they have been distributed on land. The special bulletins, broadcast throughout the day, are exhibited prominently for the passengers to read. Foreign stations also bombard the ship with news. The ship's purser has the task of sub-editing the newspaper. In an interesting paper on maritime journalism, by E. C. Thomson, in the Wireless World for March 23, it is stated that there are indications that the "wireless news 'will give place, possibly at no distant date, to a replica of a journal printed on land. This could be achieved without much difficulty by means of facsimile telegraphy. A complete page printed on land could be reproduced on board ship in a shorter time than would be required to carry the actual newspaper from one end of Fleet Street to the other.

\section{Archaological Exploration in Macedonia}

THE recently issued Annual of the British School at Athens, No. 30, covers the sessions 1928-29 and 19291930 (London: Macmillan and Co., Ltd., £3, 3s.). In addition to the annual report and financial statement, it includes the usual complement of papers by members of the School. The excavations in Macedonia have been continued, and although the account of the work carried out by Mr. W. A. Heurtley and others at Saratse provides no sensational discovery, it demonstrates the relation of cultural development in an interesting strip of country to that of the Vardar valley and the area immediately around Salonika. A Troadic site at Thermi in Lesbos was excavated by Miss W. Lamb, who describes the five successive cities of an Anatolian colony which was finally abandoned some time before the sack of Troy II. The excavations are still incomplete after two seasons' work. Messrs. J. D. and H. W. Pendlebury describe two extensive and elaborate protopalatial houses at Knossos, found at the bottom of walled pits in the west court. It is unfortunate that owing to their position they cannot be excavated, but a somewhat hazardous feat of exploration has revealed their character to a considerable extent. The first instalment of a study of the morning hymns of the Emperor Leo by Prof. H. J. W. Tillyard provides evidence on medieval methods of musical notation of considerable interest to students of early music. Mr. J. D. Beazley's "A Dancing Maenad" is a study of the grouping and meaning of figures on a Nolan amphora from Woburn Abbey. Nearly half the volume is devoted to the continuation of the final report on the School's important excavations at Sparta in 1924-28 by the former director, Mr. A. M. Woodward.

\section{Animals Playing at being Hunted}

A HAND-REARED female of the prongbuck, or American antelope, owned by Mr. L. T. Murray at Mertzon in Texas, displayed a most remarkable

$$
\text { No. } 3259 \text {, VoL. 129] }
$$


originality in getting itself hunted, as related by its owner in the Journal of Mammalogy for February, p. 41. Its habit, as it was allowed complete liberty, was to go to the main street of the little town and entice dogs to pursue it; the resulting hunt might last as long as three-quarters of an hour, at the discretion of the doe, which had so much the advantage of her pursuers in speed and intelligence that she did as she liked with them, fleeing in pretended fear, circling and waiting for them to come up, and then darting off in the opposite direction, until at last she left the pack behind and went home. It is satisfactory to learn that she came to no harm and was ultimately sent to a park and bore twins; but it would be interesting to know if playing at being hunted is a recreation indulged in by animals we usually regard as food for others, when they live in the natural state. That the hunters may play at hunting we know from what has been observed of the puma and the peregrine falcon.

\section{Excavations in Texas Caves}

THE Smithsonian Institution, it is announced through Science Service, of Washington, D.C., is sending an expedition to the caves of western Texas in charge of Mr. Frank M. Setzler, staff archæologist. The object of the expedition is to obtain evidence of the culture of the early cave dwellers of this area, and if possible to ascertain their relation to the basket makers who preceded the Pueblo-Indians of the southwestern states. Traces of the basket-makers' culture have already been found in Texas caves, but there is also evidence, in spear points of stone associated with the bones of extinct animals at some depth below the earliest basket-maker relics, of an earlier people.

\section{Modern Aids to Teaching}

A QUARTERLY review of modern aids to teaching, entitled Sight and Sound, has been published under the auspices of the British Institute of Adult Education. The first issue contains thirty pages, and is illustrated. It is edited by a committee appointed by the Institute, and its purpose is to promote in terest in the use of modern scientific inventions, such as the film, gramophone, wireless, and television, in schools and colleges and in general cultural work The gramophone and wireless have already shown their usefulness in the teaching of languages and music ; one of the articles in the issue maintains that the teaching film should be planned, made, and used in the school.

\section{New Physical Apparatus}

In their new catalogue, No. 115X, of forty pages, Messrs. Griffin and Tatlock, Ltd., give an account of some new models of physical apparatus designed for use in the teaching of physics. Under the name Microid Physical Series some twenty new designs have been produced, based for the most part on modern research methods. Each apparatus is described in a 'specification', and this is followed by 'experimental notes' which will be useful to the teacher and the student, especially as in many cases numerical results from an actual experiment are quoted. As indicating the type of apparatus included, mention may be made of the microcel thermopile, the thermo-magnet illustrating the heavy currents obtainable from thermo-elements under suitable conditions, the magnetic potentiometer (Chattock), and the moment of inertia apparatus with rotating table. Experiments are also included on light, such as the parallel plate refractometer, and heat, such as the micrometer expansion apparatus, to mention only a few of the methods described. References are given to the textbooks of Pohl, Searle, and Worsnop and Flint. Teachers of physics will find here many suggestive hints for experimental work.

\section{Announcements}

Dr. Dukinfiend H. ScotT, F.R.S., the eminent palæobotanist, has been elected a corresponding member of the Prussian Academy of Sciences.

The Faraday Medal of the Institution of Electrical Engineers will be presented to Sir Oliver Lodge at the ordinary meeting of the Institution to be held on April 21 at 6 P.M. The presentation will precede the twenty-third Kelvin Lecture, which will be delivered by Dr. W. E. Sumpner, on "The Work of Oliver Heaviside".

UNDER the auspices of the British Science Guild, Prof. S. Chapman, professor of mathematics at the Imperial College of Science and Technology, will deliver a popular lecture on "Polar Lights", on Wednesday, May 25, at 5 P.M. The lecture will be at the Royal Society of Arts, John Street, Adelphi, W.C.2. Tickets, for which no charge is made, can be obtained on application to the Secretary, British Science Guild, 6 John Street, Adelphi, W.C.2.

The Dyers' Company Gold Research Medal for the period 1930-31 has been awarded to Prof: F. M. Rowe, professor of colour chemistry and dyeing in the University of Leeds, for a series of three papers on the chemical and physical effects of kier boiling on insoluble azo colours on the fibre. This is the third occasion on which Prof. Rowe has received this medal, the earlier awards being made for the periods 1924-25 and 1926-27 for his investigations of other aspects of the chemistry of azo colouring matters.

Prof. W. L. BragG, F.R.S., professor of physics, Victoria University of Manchester ; the Rev. Canon H. Maynard Smith, Canon Residentiary of Gloucester ; and the Right Hon. J. H. Whitley, chairman of the British Broadcasting Corporation, formerly Speaker of the House of Commons, have been elected members of the Athenæum under the provisions of Rule II. of the Club, which empowers the annual election by the committee of a certain number of persons of distinguished eminence in science, literature, the arts, or for public service.

THE following appointments to the Colonial Agricultural Service have recently been made by the Secretary of State: Mr. W. E. Bassett, formerly assistant superintendent, Victoria Botanic Gardens, Nigeria, to be assistant agricultural officer, Dominica ; Mr. T. R. Hayes, superintendent of agriculture, Gambia, to be agricultural officer, Uganda; $\mathrm{Mr}$. F. L. Squibbs, assistant agricultural officer, Leeward 